\title{
The direct medical costs of epilepsy in children and young people: A population-based study of health resource utilisation
}

Mostafa A. Sayed Ali ${ }^{1,2}$, Rachel A. Elliott ${ }^{1}$, and Laila J. Tata ${ }^{3}$

${ }^{1}$ Division of Social Research in Medicines and Health, School of Pharmacy, University of Nottingham, Nottingham, United Kingdom.

${ }^{2}$ Faculty of Pharmacy, Assiut University, Assiut, Egypt

${ }^{3}$ Division of Epidemiology and Public Health, School of Medicine, University of Nottingham, Nottingham, United Kingdom.

Correspondence: Mostafa A. Sayed Ali

Faculty of Pharmacy, Assiut University, Assiut 71526, Egypt

Email: mostrahman79@yahoo.com, mostrahman79@gmail.com,

Telephone: 00201011680280

Fax: +20882332776

Summary: 275 words

Body text (introduction, methods, results, discussion): 3,870 words

Figures: 2

Tables: 4 


\begin{abstract}
We described the health resource utilisation (HRU) and associated direct medical costs of managing epilepsy in children and young people (CYP) using populationlevel data from the United Kingdom.
\end{abstract}

The study cohort were CYP born between 1988 and 2004 who were newly diagnosed with epilepsy and identified using a nationally representative primary care database from the United Kingdom. Reference unit costs were applied to each element of HRU to calculate annual direct medical costs per child. We assessed whether HRU and costs differed by time from diagnosis, age, sex and socioeconomic deprivation.

Of 798 CYP newly diagnosed with epilepsy, $56 \%$ were male and the mean age at diagnosis was 5.6 years. The highest burden of HRU was in the first year following diagnosis with a mean annual cost of $£ 930$ (95\% confidence interval (CI) £839$1,022)$ per child in this first year. This decreased to $£ 461$ (95\%CI 368-551) in the second year which remained fairly constant each subsequent year (£413 (95\% CI $282-540)$ in the $8^{\text {th }}$ year). The highest contribution to the annual medical costs was from inpatient hospital admissions followed by the costs of AEDs. Mean annual medical costs were significantly higher in children under 6 years of age compared with older children $(\mathrm{p}<0.01)$, but were similar across socioeconomic groups $(p=0.62)$.

The direct medical costs of HRU in CYP with epilepsy are higher in the first year after diagnosis compared to subsequent years, reflecting HRU related to the diagnostic process in the first year. Medical costs did not vary substantially by sex or 
socioeconomic deprivation indicating a similar level of consultation and care across these groups.

Keywords: Epilepsy in children, general practice, medical cost, health resource 


\section{Introduction}

Epilepsy is a serious chronic neurological disorder that has a higher incidence (70116 per 100,000 person-years) in children and young people (CYP), under 18 years, than in adults (30-55 per 100,000 person-years) (Forsgren et al., 2005; Kotsopoulos et al., 2002; Meeraus et al., 2013). As many clinical subtypes of childhood epilepsy persist into adulthood (Guerrini 2006), epilepsy has long term clinical care requirements and a high economic burden at individual, family, health service and societal levels in the United Kingdom (UK) and in Europe (Pugliatti et al., 2007).

The total direct medical cost of epilepsy to the United Kingdom (UK) National Health Service (NHS) was estimated to be $£ 170$ million in 1994 when the population was 59.8 million people (Cockerell et al., 1994). This included antiepileptic drug (AED) treatment, outpatient attendances, inpatient hospital admissions, diagnostic imaging, blood chemistry tests, general practitioner and specialist consultations. This estimate was based on aggregated data of 1628 adults and children with epilepsy. In 2005, Beghi et al reviewed published studies on the cost of childhood epilepsy and concluded that there was very limited knowledge of the economic impact of epilepsy in CYP due to the scarcity, inconsistency and poor comparability of published articles (Beghi et al., 2005) and no subsequent studies have estimated these costs at a population level in the UK.

Nevertheless, there are appear to be wide differences in incidence, prognosis and management between adults and CYP with epilepsy (Beghi et al., 2005). Studies of health resource utilisation (HRU) in regions of Canada and Wales have indicated that CYP under 18 years of age are more likely than adults to see neurologists, visit emergency departments, and have more inpatient and outpatient hospital admissions 
(Jette et al., 2008; Morgan et al., 2000). Studies in these populations, consisting mainly of adults, also showed HRU differences by sociodemographic factors, such as increased hospital care utilisation for epilepsy in those with higher socioeconomic deprivation in Wales (Jette et al., 2008; Morgan et al., 2000). These studies, however, did not assess relationships specifically in CYP nor did they estimate any associated costs, which are required to inform service configuration and evaluation for CYP. Updated HRU and cost data should help service planning and provision by understanding whether there are areas where cost budgets need to be rebalanced between epilepsy diagnosis, treatment and acute management and services. In addition, identifying whether and how epilepsy HRU and costs differ across sociodemographic groups is crucial for planning area-level population service provisions and modifications.

Epilepsy in the UK is managed principally via primary care in collaboration with secondary care settings (Stokes et al., 2004). The aim of our study was to use a large population-based general practice database to estimate patient-level direct medical costs of managing epilepsy in CYP. We also assessed whether HRU and direct medical costs varied by age, sex, socioeconomic status and the time from diagnosis of epilepsy. 


\section{Methods}

\subsection{Data Source}

Data were extracted from The Health Improvement Network (THIN), a computerised primary care database that contained longitudinal electronic medical records from 255 general practices across the UK at the time data were extracted. In 2004, THIN had approximately 3.2 million patients which, covered $5.3 \%$ of the UK population (THIN, 2012). Data in THIN include anonymised patient records with demographic information, medical diagnoses (including those resulting from referrals to specialists), prescriptions, laboratory results, records of hospital admissions and medical measurements. Diagnoses and investigations are recorded using Read codes which have a hierarchical structure and include comprehensive clinical terminology (Stuart-Buttle et al., 1996).

\subsection{Study population}

From an initial population of all CYP born between January $1^{\text {st }}, 1988$ and November $30^{\text {th }}, 2004$, we identified all CYP (up to age 16 years) with newly diagnosed epilepsy. We defined CYP as having epilepsy if they had at least one diagnostic Read code for epilepsy, selected according to consistency with the 1989 International League Against Epilepsy (ILAE 1989) and section G40 of the International Statistical Classification of Diseases, $10^{\text {th }}$ Revision, and at least one prescription for an AED shown in Table 1. To avoid misdiagnosis of epilepsy, We excluded codes of disorders that mimic epilepsy such as febrile convulsions and we also excluded antiepileptic drugs prescribed for diseases other than epilepsy (Ali 2012). Our code lists were constructed with consultation from a Clinical Associate Professor of Paediatric Neurology in the Division of Child Health, the University of 
Nottingham's Queen Medical Centre. In addition, to be considered as incident cases their first epilepsy diagnosis and any related treatment had to occur at least 6 months after their date of registration with the general practice to be considered as newly diagnosed, unless they had been registered within the first 6 months of life (70\% of the population were registered within 6 months of birth). We also included only CYP who had at least one year of registered follow-up data and CYP were followed up to 8 years after their initial diagnosis of epilepsy or, if earlier, to their date of death, the date when they transferred out of the general practice or the last date of data collection on November $30^{\text {th }}, 2004$. We extracted information from the CYP's records on their age, sex, and socioeconomic deprivation. Age was calculated at the beginning of each year as a time-varying variable and categorised into four groups $(<$ 2, 2-6, 7-12 and > 12 years) based on the British National Formulary (BNF 2011) age-specific dosage indications for CYP with epilepsy. The Townsend index, in quintiles, which is an area-based measure derived from 2001 census data linked to patients' post codes, was used as a measure of household-level socioeconomic deprivation (Jordan et al., 2004). Some cases were diagnosed to have benign epilepsy syndromes who were occasionally prescribed anticonvulsant medication in their therapeutic files. Therefore, all health resources they consumed were included in the calculation of the cost of epilepsy.

\subsection{Information on heath resource use}

The following elements of HRU were extracted from all patients' records:

General practice (GP) consultations: The number of consultations on unique days

Outpatient hospital care: Read codes for outpatient attendances including referrals to paediatric neurology were extracted from the medical files. Specific recording of 
paediatric neurology attendances, however, were only found for $3 \%$ of the study population, suggesting that they were systematically under-recorded or lacked specificity in coding of these attendances. The 2004 NICE guideline for diagnosis and management of epilepsy (Stokes et al., 2004) recommended that the diagnosis of epilepsy is established by a neurologist or a paediatric specialist in epilepsy.

Therefore, we included one paediatric neurologist appointment per CYP in the first year following epilepsy diagnosis if it was not recorded in the patient's medical record.

Inpatient and emergency hospital care: Read codes for hospital admissions were categorised into inpatient admissions which included elective or planned patient admission and non-elective admission (unplanned admission). Emergency hospital care also included the non-admitted accident and emergency (A\&E) department visits. This classification was based on the 2011 Department of Health- reference costs guideline (Department of Health, 2011).

Diagnostic imaging: Read codes for diagnostic imaging were extracted and principally included electroencephalogram (EEG), computerised tomography (CT) and magnetic resonance imaging (MRI). Read codes referring to EEG details such as prolonged ambulatory or video telemetry EEG were not identified. Therefore the unit cost of routine EEG were attached to the calculated cost data.

Blood chemistry tests: Codes for relevant biochemistry tests for monitoring blood levels of AEDs were used to identify monitoring activity.

Prescribed medications for epilepsy: All prescriptions for older (approved before 1990) and newer (approved after 1990) AEDs were identified and extracted from CYP's therapy records using the British National Formulary for children (BNF 
2011) codes for AEDs. The data included information on the quantity prescribed, formulation and dosage strength.

\section{Cost information and assigning costs to heath resource use}

To assign costs to each element of HRU we used the most up-to-date Department of Health Reference Costs at the time of our study (Department of Health, 2011), the Personal Social Services Research Unit (PSSRU) Costs of Health and Social Care (Curtis 2011), the BNF for children (BNF 2011) and the NHS Electronic Drug Tariff 2011(NHS Electronic Drug Tariff, 2011) which are summarised in Table 1 to show the unit cost of each element of HRU.

The unit cost of a GP consultation was obtained using the average unit cost per a GP visit lasting 11.7 minutes without qualifications and including direct care staff costs. The costs of AEDs were calculated for each prescription by multiplying the price guidance obtained from the BNF for children 2011 for each drug formulation by the quantity prescribed. For example, if a child was prescribed $600 \mathrm{ml}$ of sodium valproate liquid and the unit price in the BNF was $£ 6.13$ for $300 \mathrm{ml}$-pack, the cost of this prescription was calculated as $2 \mathrm{x} £ 6.13=£ 12.26$. Formulations for clobazam, clonazepam, midazolam and paraldehyde (which accounted for $1 \%$ of all prescriptions) are extemporaneous preparations and are usually provided by special orders. The costs of these formulations were obtained from the NHS Electronic Drug Tariff 2011.

\subsection{Statistical analyses of health resource use and associated costs}

For each element of HRU, we calculated the annual mean utilisation per CYP with epilepsy for each year following diagnosis. We also calculated the mean direct costs of each HRU element per child per year, starting from the date of diagnosis, by 
multiplying the number of units of each element per year by the fixed unit cost values. We calculated the arithmetic mean of the cost of each element as this provides information about the total costs required to treat all patients and so is considered the most useful measure for health care policy decisions (Briggs and Gray 1998). We similarly calculated the arithmetic mean of the total cost of hospital care (comprised of inpatient and outpatient hospital care episodes, diagnostic imaging and blood chemistry tests), the total cost of AED prescriptions, and the overall total direct cost per child each year.

Since cost data are typically right skewed due to a small number of high cost outliers in any patient cohort, nonparametric bootstrapping with replacement was adopted as the method to achieve an approximate normal distribution and to enable comparison of arithmetic means of the cost data (Briggs and Gray 1998). On the data generated by bootstrapping, unpaired t-tests were used to compare the annual total costs between males and females. Analysis of variance was used to compare the annual costs between age groups and quintiles of the Townsend index. Cost estimates were calculated in UK pound sterling (GBP) and converted to US dollars and Euros using the exchange rates on December $31^{\text {st }}, 2011$. All analyses were carried out using STATA V.11 (StataCorp, College Station, Texas, USA). 


\section{Results}

\subsection{Study population}

From the initial study population of 528,760 CYP, 2020 (0.4\%) had epilepsy according to our definition and 798 of these were newly diagnosed incident cases during the study period who also had at least one year of data following diagnosis (mean 6 years of follow up, Standard Deviation (SD) 3.6). Seventy percent (560) of the incident cases had their registration date at or within 6 months of their date of birth. Of the incident cases, $444(56 \%)$ were male and the age at diagnosis ranged from 1 day to 15.5 years (mean age was 5.6 years; $\mathrm{SD}=3.8$ ).

\subsection{Health resource utilisation and associated costs}

The HRU each year following epilepsy diagnosis is described in Table 2. Apart from A\&E visits and AED prescriptions, the mean number of annual GP consultations, outpatient attendances, inpatient admissions, diagnostic imaging and blood chemistry tests per CYP were all highest in the first year following diagnosis. The mean number of AED prescriptions per CYP remained almost unchanged over the years following diagnosis. Inpatient admissions, A\&E visits and diagnostic imaging occurred less than yearly for the majority of patients, over most years of follow-up. Of diagnostic tools, EEG were more likely used than MRI and CT scans.

The direct medical costs of HRU each year following epilepsy diagnosis are shown in Table 3. The mean total direct cost per CYP was $£ 930$ (95\% CI £839-1,022) in the first year following diagnosis and ranged from $£ 368$ (95\% CI £264-473) to $£ 587$ (95\% CI £300-873) in consecutive follow-up years. Each year, small proportions (4$11 \%$ ) of CYP had a high total direct cost of more than $£ 2000$.

For every year, hospital care costs comprised the largest contribution to the total 
direct cost per child followed by the cost of AED prescriptions (Figure 1). In the first year, hospital care costs accounted for $80 \%$ of the total direct medical costs and then ranged from $45 \%$ to $67 \%$ in consecutive years, inpatient admissions accounted for most of these (33\% to $59 \%$ of the total direct costs). Over the years of follow-up, AED prescriptions accounted for $13 \%$ to $50 \%$ and GP consultations accounted for $4 \%$ to $8 \%$ of the total direct medical costs.

The annual costs of AEDs per child increased from $£ 118$ (95\% CI $£ 100-137)$ in the first year to $£ 208$ (95\% CI £160-257) in the eighth year following diagnosis with newer AEDs accounting for a larger proportion of the costs over time (Table 3 and Figure 2).

Table 4 shows the variation of the annual medical costs of HRU by sociodemographic factors of CYP. The mean total medical costs per child were higher for males compared with females, but this was only statistically significant in the first year following diagnosis when costs in females were $80 \%$ of the mean cost in males ( $£ 808$ versus $£ 1,027$ in males; $t$-test on bootstrapped data, $p$ values for each year are shown in Table 4). The study cohort included only four patients with age at diagnosis in the neonatal period (up to 28 days). Therefore, the cost of neonatal epilepsy management was calculated and added to that of the age range of infancy. The mean total direct medical costs per child were higher in younger age groups than in older age groups, which remained over the 4 years following diagnosis. (ANOVA test, p-values for each year are shown in Table 4). The total medical costs did not vary by Townsend deprivation quintiles (ANOVA test, $\mathrm{p}$ values for each year are shown in Table 4). 


\section{Discussion}

We have shown that the HRU and direct medical costs of CYP newly diagnosed with epilepsy are high although there are variations based on the investigations required, hospital care and AED treatment plan. Costs are highest in the first year following diagnosis but subsequent annual costs remain stable, without decreases, regardless of the age at diagnosis. Annual costs are spread across most elements of HRU, particularly with primary care consultations, inpatient and outpatient hospital care, and AED prescriptions remaining consistent in the years following diagnosis. Costs of HRU were lower in girls compared with boys by a modest amount, although in the first year following diagnosis costs in girls were only $80 \%$ of those in boys. Annual direct medical costs decreased with increasing age, however, there were no differences by socioeconomic deprivation indicating similar consultation and care across these groups.

Variation in HRU and associated medical costs among CYP likely reflects the heterogenic nature of epilepsy in terms of diagnosis, seizure severity and response to treatment. For example, some CYP with uncontrolled (drug-resistant) seizures may lead to more hospital care services and/or higher AED costs. Unfortunately, it was not possible to assess HRU by diagnostic subtypes of epilepsy or by seizure severity because these data were not recorded with adequate specificity for the majority of our cohort in their general practice records. A previous survey study investigated the association between the cost and severity of seizures in 696 adults and 93 CYP under16 years (Jacoby et al., 1998) and reported that patients with more frequent seizures consumed more than one-half of total combined costs of direct and indirect care for epilepsy. The annual total direct health care cost (adult and children combined) was $£ 689$ per patient, ranging from $£ 162$ for patients with no seizures to 
$£ 1525$ for those with $>1$ seizure per month.

Apart from initial paediatric neurologist consultations, which should form part of the diagnostic process, the highest contribution to the annual direct medical costs of epilepsy was that of inpatient hospital admissions followed by AED prescriptions. This contribution of HRU elements to total direct medical costs is consistent with that found in Cockrell et al's study, a prospectively followed cohort of 602 patients of all ages ( $25 \%$ of whom were under age 15 years) identified from general practices throughout the UK (Cockerell et al., 1994). Similar to our findings, the authors calculated higher total costs in the first year of follow-up (£611) than in successive years (e.g. $£ 169$ in the $8^{\text {th }}$ year). The authors did not provide separate cost data for epilepsy in children; only combined costing data for the adults and children were presented. In another study, Jacoby et al estimated similar patterns of the contribution of HRU to the total direct costs to that of our study where the cost of inpatient hospital admissions was 58\%, followed by AEDs (23\%), outpatient attendances (7\%) and GP consultations (2\%) over a 12-month period (Jacoby et al., 1998). In contrast to our longitudinal study, their design was a cross-sectional survey estimating the costs of epilepsy for one year and included only 93 CYP less than 16 years old. Most information was based on patient questionnaires and GP medical records, which may have been subject to some inaccurate recall.

The comparisons of our HRU and direct medical costs to that of CYP from different countries is difficult because of monetary differences and variation in policies for public and private health care systems. For example, an Italian study prospectively followed 189 CYP for 12 months and reported higher rates of hospitalisations and investigations than our study (Guerrini et al., 2001). The authors showed that the annual HRU such as investigations (e.g. mean EEG 1.8-3.5 per child) and hospital 
admissions were higher in newly diagnosed CYP with epilepsy and those with drugresistant epilepsy. The annual cost per child was estimated at $€ 1,635$ which corresponds to $£ 1,349$, compared to our estimate of $£ 930$ in the first year following diagnosis.

\subsection{Medical costs and CYP's sociodemographics}

The total direct costs per child were slightly higher in boys than in girls, although this was mostly in the first year following diagnosis. Although we were not able to assess clinical epilepsy subtype, this does not indicate that there are such substantial sex differences. The direct medical costs per child were significantly different across age groups of CYP and tended to be higher in younger age groups ( $<2$ and $2-6$ years) who comprised $65 \%$ of our cohort. Higher costs were attributed to more frequent hospitalisations and visits to the emergency departments. This probably because the age of onset of some drug-resistant epilepsy subtypes (e.g. West syndrome and Dravet's syndrome) which manifest more frequent seizures is at infancy and early childhood (Guerrini 2006). Very similar findings regarding age groups were reported when the costs of hospital care were estimated for 3,892 people (mostly adults) with epilepsy resident in Wales, UK (Morgan and Kerr 2004). A Canadian study of 1,431 patients with epilepsy reporting health resource utilisation (HRU) over 1 year but not the associated costs, also suggested that CYP with epilepsy under 18 years of age were more likely than adults to see neurologists, visit emergency departments and be admitted to hospital (Jette et al., 2008).

In our UK-wide study population, we did not find variation in total medical costs by socioeconomic deprivation, which indicates that the quality of care provided was the same for all CYP regardless of the area they lived in. A previous study reported a 
weak correlation between deprivation and hospital care activity $(r=0.59,(p<0.001)$ for inpatient admissions and for outpatient appointments: $\mathrm{r}=0.51(\mathrm{p}=0.001)$ among 2,028 patients with epilepsy (Morgan et al., 2000). However, the data of this study were combined for adults and children and limited to hospital care utilisation in the health district of South Glamorgan, Wales, UK. The authors investigated prevalent cases of mostly adults with epilepsy (1996 estimate) which may have involved more medication non-adherence and/or severity of seizures.

\subsection{Strengths and limitations of the study}

This is one of few prospective studies estimating HRU and associated costs of epilepsy in a general population setting and, to our knowledge, the first to describe epilepsy only in CYP according to their sociodemographic variation. The study cohort was identified from a national population-based database, so the findings can be generalised to CYP with epilepsy in the UK. This study calculated the direct medical costs of CYP with epilepsy from initial diagnosis and over time and not only in the first year like some studies where the costs have been reported higher in the first year than for subsequent years. Our study provides new data to the scarcity of cost of illness studies in CYP with epilepsy. As we were including only new cases of epilepsy, cases were required to have both a diagnosis and prescriptions for AEDs, a similar but slightly more specific definition than that used by Meeraus et al (Meeraus et al., 2013) also using the THIN general practice database. There are no standard ways to identify clinical epilepsy using routine health data and no specific studies that have assessed their sensitivity and specificity in children, however, we assessed the external validity of our definition by comparing our cohort's incidence and prevalence (Ali 2012) to that of a UK Clinical Practice Research Datalink study for the same age range of children (Wallace et al., 1998). 
A number of limitations have been encountered in this study. First because of routine data may not identify all health resources required, assumptions have been made to correct for the lower recoding of neurologist outpatient appointments. For example, the cost of one paediatric neurology visit per child was added in the first year; this was considered reasonable based on the recommendations of NICE Guideline 2004 for diagnosis and management of epilepsy in CYP (Stokes et al., 2004), although the actual neurologist consultations may have been underestimated for subsequent years following diagnosis. Furthermore, the costs of hospital care were estimated from the mean costs per episode as it was not possible to distinguish between epilepsy-related and non-epilepsy related hospital care in THIN. Morgan et al's previous study, however, indicated that differentials between patients with and without epilepsy were very high for CYP compared with adults (Morgan and Kerr 2004).

Despite these limitations, this study indicates that epilepsy represents a significant economic burden to the health care provider. This study provides baseline data for further economic evaluations on the burden of epilepsy in CYP. Prospective data collection on the specialists' appointments and hospital care may be required for future analysis of the direct medical costs of treating epilepsy.

\section{Conclusions}

The mean direct medical costs of managing epilepsy in CYP were higher in the first year of diagnosis than the consecutive years due to diagnostic process. The largest element of HRU contributed to the total direct medical costs of epilepsy was inpatient hospital care, followed by the costs of AEDs. Direct medical costs significantly decreased with age, but were similar between boys and girls and across socioeconomic groups. 


\section{Acknowledgement}

The authors would like to thank the Egyptian government for funding Mostafa Ali's $\mathrm{PhD}$ degree which is the basis of this study. We are also grateful to Dr. William Whitehouse, a clinical associate Professor in the Division of Child Health, at the University of Nottingham's Queen's Medical Centre for his clinical input in how to best identify clinically diagnoses of epilepsy in children.

Disclosure statement: the authors have no conflicts of interest to declare.

Ethical approval for the research project was granted from the THIN internal Scientific Review Committee (SRC), Reference Number: 09-00. We affirm that the manuscript is consistent with the Journal's guidelines for ethical publication. 
Table 1: Unit cost of health care resources

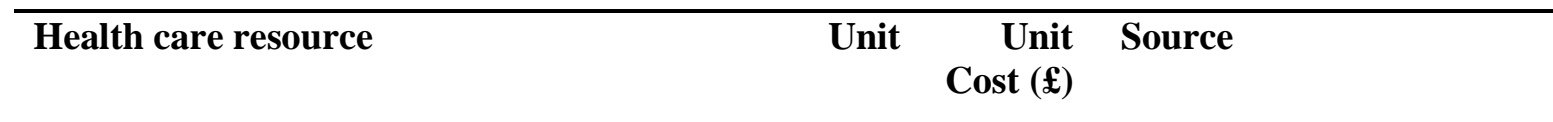

\section{GP consultation}

\section{Hospital care episodes}

Paediatric neurology outpatient attendances

Other outpatient attendances

Elective inpatient admissions

Non-elective inpatient admissions (e.g.

emergency admission)

$A \& E$ visits (with no inpatient stay)

\section{Diagnostic imaging}

CT

EEG

MRI

\section{Blood chemistry tests}

Older AEDs
1354 DH Reference Costs 2011

1101 DH Reference Costs 2011

13091 DH Reference Costs 2011

1568 DH Reference Costs 2011

108 DH Reference Costs 2011

95 DH Reference Costs 2011

93 DH Reference Costs 2011

163 DH Reference Costs 2011

1 DH Reference Costs 2011

Carbamazepine, clobazam, ethosuximide,

phenobarbital, phenytoin, primidone and sodium

BNF for children 2011

valproate preparations

Clobazam suspension $5 \mathrm{mg} / 5 \mathrm{ml}$

$100 \mathrm{ml}$

NHS Electronic Drug Tariff

Clonazepam oral drops $2.5 \mathrm{mg} / \mathrm{ml}$

$20 \mathrm{ml}$

Clonazepam suspension $500 \mu \mathrm{g} / 5 \mathrm{ml}$

$100 \mathrm{ml}$

Midazolam buccal solution $10 \mathrm{mg} / \mathrm{ml}$

$25 \mathrm{ml}$

Paraldehyde injection

$10 \mathrm{ml}$

\section{Newer AEDs}

Lamotrigine, Levetiracetam, topiramate,

BNF for children 2011

gabapentin, oxcarbazepine, tiagabine and

vigabatrin preparations

AEDs: antiepileptic drugs; A\&E: accident and emergency; BNF: British National Formulary; CT: computerised tomography; DH: Department of Health; GP: general practitioner; EEG: electroencephalogram; MRI: magnetic resonance imaging; NHS: National Health Service; PSSRU: Personal Social Services Research Unit 
Table 2: Mean health resource utilisation per child for CYP with epilepsy

\begin{tabular}{|c|c|c|c|c|c|c|c|c|c|c|}
\hline \multirow{2}{*}{$\begin{array}{l}\text { Years after } \\
\text { epilepsy } \\
\text { diagnosis }\end{array}$} & \multirow{2}{*}{$\begin{array}{r}\text { Number } \\
\text { of CYP }\end{array}$} & \multirow{2}{*}{$\begin{array}{r}\text { GP consultations } \\
\text { (SD) }\end{array}$} & \multicolumn{3}{|c|}{ Hospital care episodes (SD) } & \multicolumn{3}{|c|}{ Diagnostic imaging (SD) } & \multirow{2}{*}{$\begin{array}{r}\text { Blood } \\
\text { chemistry } \\
\text { tests }\end{array}$} & \multirow{2}{*}{$\begin{array}{r}\text { Prescriptions of } \\
\text { AEDs (SD) }\end{array}$} \\
\hline & & & Outpatient & Inpatient & $\mathrm{A} \& \mathrm{E}$ & $\mathrm{CT}$ & EEG & MRI & & \\
\hline $1^{\text {st }}$ & 798 & $\begin{array}{r}2.28 \\
(2.48)\end{array}$ & $\begin{array}{r}0.34 \\
(1.18)\end{array}$ & $\begin{array}{r}0.10 \\
(0.39)\end{array}$ & $\begin{array}{r}0.09 \\
(0.86)\end{array}$ & $\begin{array}{r}0.03 \\
(0.14)\end{array}$ & $\begin{array}{r}0.12 \\
(0.38)\end{array}$ & $\begin{array}{r}0.08 \\
(0.32)\end{array}$ & $\begin{array}{r}0.05 \\
(0.27)\end{array}$ & $\begin{array}{r}11.40 \\
(8.46)\end{array}$ \\
\hline $2^{\text {nd }}$ & 754 & $\begin{array}{r}0.94 \\
(1.53)\end{array}$ & $\begin{array}{r}0.25 \\
(0.93)\end{array}$ & $\begin{array}{r}0.07 \\
(0.40)\end{array}$ & $\begin{array}{r}0.08 \\
(0.64)\end{array}$ & $\begin{array}{r}0.01 \\
(0.03)\end{array}$ & $\begin{array}{r}0.03 \\
(0.18)\end{array}$ & $\begin{array}{r}0.03 \\
(0.20)\end{array}$ & $\begin{array}{r}0.04 \\
(0.33)\end{array}$ & $\begin{array}{r}12.45 \\
(9.57)\end{array}$ \\
\hline $3^{\text {rd }}$ & 653 & $\begin{array}{r}0.83 \\
(1.42)\end{array}$ & $\begin{array}{r}0.18 \\
(0.76)\end{array}$ & $\begin{array}{r}0.08 \\
(0.48)\end{array}$ & $\begin{array}{r}0.09 \\
(0.45)\end{array}$ & $\begin{array}{r}0.01 \\
(0.04)\end{array}$ & $\begin{array}{r}0.04 \\
(0.22)\end{array}$ & $\begin{array}{r}0.01 \\
(0.12)\end{array}$ & $\begin{array}{r}0.03 \\
(0.20)\end{array}$ & $\begin{array}{r}12.03 \\
(10.31)\end{array}$ \\
\hline $4^{\text {th }}$ & 530 & $\begin{array}{r}0.77 \\
(1.37)\end{array}$ & $\begin{array}{r}0.23 \\
(0.92)\end{array}$ & $\begin{array}{r}0.06 \\
(0.46)\end{array}$ & $\begin{array}{r}0.05 \\
(0.34)\end{array}$ & $\begin{array}{r}0.01 \\
(0.06)\end{array}$ & $\begin{array}{r}0.04 \\
(0.19)\end{array}$ & $\begin{array}{r}0.04 \\
(0.30)\end{array}$ & $\begin{array}{r}0.04 \\
(0.21)\end{array}$ & $\begin{array}{r}12.18 \\
(11.02)\end{array}$ \\
\hline $5^{\text {th }}$ & 400 & $\begin{array}{r}0.73 \\
(1.07)\end{array}$ & $\begin{array}{r}0.21 \\
(0.73)\end{array}$ & $\begin{array}{r}0.11 \\
(0.92)\end{array}$ & $\begin{array}{r}0.09 \\
(0.41)\end{array}$ & $\begin{array}{r}0.01 \\
(0.05)\end{array}$ & $\begin{array}{r}0.04 \\
(0.20)\end{array}$ & $\begin{array}{r}0.02 \\
(0.14)\end{array}$ & $\begin{array}{r}0.02 \\
(0.19)\end{array}$ & $\begin{array}{r}12.29 \\
(11.20)\end{array}$ \\
\hline $6^{\text {th }}$ & 319 & $\begin{array}{r}0.64 \\
(1.13)\end{array}$ & $\begin{array}{r}0.13 \\
(0.58)\end{array}$ & $\begin{array}{r}0.05 \\
(0.28)\end{array}$ & $\begin{array}{r}0.09 \\
(0.43)\end{array}$ & $\begin{array}{r}0.00 \\
(0)\end{array}$ & $\begin{array}{r}0.02 \\
(0.16)\end{array}$ & $\begin{array}{r}0.03 \\
(0.20)\end{array}$ & $\begin{array}{r}0.03 \\
(0.18)\end{array}$ & $\begin{array}{r}12.06 \\
(12.55)\end{array}$ \\
\hline $7^{\text {th }}$ & 223 & $\begin{array}{r}0.65 \\
(1.40)\end{array}$ & $\begin{array}{r}0.19 \\
(0.68)\end{array}$ & $\begin{array}{r}0.05 \\
(0.35)\end{array}$ & $\begin{array}{r}0.15 \\
(0.79)\end{array}$ & $\begin{array}{r}0.00 \\
(0)\end{array}$ & $\begin{array}{r}0.05 \\
(0.25)\end{array}$ & $\begin{array}{r}0.04 \\
(0.17)\end{array}$ & $\begin{array}{r}0.01 \\
(0.16)\end{array}$ & $\begin{array}{r}12.05 \\
(12.24)\end{array}$ \\
\hline $8^{\text {th }}$ & 175 & $\begin{array}{r}0.78 \\
(1.60)\end{array}$ & $\begin{array}{r}0.15 \\
(0.50)\end{array}$ & $\begin{array}{r}0.05 \\
(0.24)\end{array}$ & $\begin{array}{r}0.13 \\
(0.53)\end{array}$ & $\begin{array}{r}0.00 \\
(0)\end{array}$ & $\begin{array}{r}0.03 \\
(0.13)\end{array}$ & $\begin{array}{r}0.03 \\
(0.17)\end{array}$ & $\begin{array}{r}0.03 \\
(0.21)\end{array}$ & $\begin{array}{r}12.00 \\
(12.63)\end{array}$ \\
\hline
\end{tabular}

AEDs: antiepileptic drugs; A\&E: accident and emergency; CT: computerised tomography; CYP: children and young people; GP: general practitioner; EEG:

electroencephalogram; MRI: magnetic resonance imaging; SD: standard deviation. 
Table 3: Mean direct medical costs per child for CYP with epilepsy

\begin{tabular}{|c|c|c|c|c|c|c|c|c|}
\hline \multicolumn{9}{|c|}{ Years after epilepsy diagnosis (number of CYP) } \\
\hline Cost category & $\mathbf{1}^{\text {st }}(\mathrm{n}=798)$ & $2^{\text {nd }}(n=754)$ & $3^{\text {rd }}(n=653)$ & $4^{\text {th }}(n=530)$ & $5^{\text {th }}(n=400)$ & $6^{\text {th }}(n=319)$ & $7^{\text {th }}(n=223)$ & $8^{\text {th }}(n=175)$ \\
\hline \multicolumn{9}{|c|}{ Mean cost per child* $(95 \%$ confidence interval) } \\
\hline \multicolumn{9}{|l|}{ Hospital care episodes } \\
\hline Paediatric neurology & $354(0)$ & 0 & 0 & 0 & 0 & 0 & 0 & 0 \\
\hline Inpatient admissions & $306(223-390)$ & $230(19-32)$ & $241(126-351)$ & $187(65-308)$ & $349(68-629)$ & $136(51-239)$ & $166(23-310)$ & $141(33-250)$ \\
\hline A\&E visits & $19(10-28)$ & $11(4-17)$ & $17(9-26)$ & $11(4-17)$ & $13(7-23)$ & $13(6-21)$ & $20(5-34)$ & $18(5-32)$ \\
\hline \multicolumn{9}{|l|}{ Diagnostic imaging } \\
\hline $\mathrm{CT}$ & $2(1-3)$ & 0 & $0.2(4)$ & $0.4(0.1-0.9)$ & $0.5(0.2-0.7)$ & 0 & 0 & 0 \\
\hline EEG & $11(9-14)$ & $3(2-4)$ & $4(2-5)$ & $3(2-5)$ & $4(2-6)$ & $2(0.1-3)$ & $4(1-7)$ & $2(1-3)$ \\
\hline MRI & $12(9-16)$ & $6(3-8)$ & $2(0.5-4)$ & $7(3-11)$ & $3(0.2-5)$ & $5(1-8)$ & $5(1-9)$ & $5(1-9)$ \\
\hline Blood chemistry tests & $0.1(0.3)$ & $0.1(0.3)$ & $0.1(0.2)$ & $0.1(0.2)$ & $0.1(0.2)$ & $0.1(0.2)$ & $0.1(0.1)$ & $0.1(0.2)$ \\
\hline \multicolumn{9}{|l|}{ AEDs } \\
\hline New AEDs & $24(18-30)$ & $50(40-59)$ & $61(49-73)$ & $70(56-84)$ & $71(53-88)$ & $82(59-104)$ & $108(74-142)$ & $117(72-161)$ \\
\hline $\begin{array}{l}\text { Total cost of hospital } \\
\text { care per child }\end{array}$ & $739(651-827)$ & $276(186-365)$ & $281(166-397)$ & $232(107-357)$ & $393(112-675)$ & $177(79-275)$ & $217(70-365)$ & $184(71-296)$ \\
\hline $\begin{array}{l}\text { Total cost of AEDs per } \\
\text { child }\end{array}$ & $118(100-137)$ & $157(141-174)$ & $170(147-193)$ & $177(154-200)$ & $173(148-198)$ & $174(146-203)$ & $194(159-230)$ & $208(160-257)$ \\
\hline \multirow{3}{*}{$\begin{array}{l}\text { Total direct medical cost } \\
\text { per child }\end{array}$} & $£ 930(839-1022)$ & $£ 461(368-551)$ & $£ 475(353-591)$ & $£ 430(300-561)$ & $£ 587(300-873)$ & $£ 368(264-473)$ & $£ 429(273-579)$ & $£ 413(282-540)$ \\
\hline & \$1437 (1297-1580) & $\$ 713(569852)$ & $\$ 734(546-913)$ & $\$ 665(464-867)$ & $\$ 907$ (464-1349) & $\$ 569(408-731)$ & $\$ 663(422-895)$ & $\$ 638(436-835)$ \\
\hline & $€ 1110(1001-1220)$ & $€ 550(439-658)$ & $€ 567(421-705)$ & $€ 513(358-670)$ & $€ 701(358-1042)$ & $€ 439(315-565)$ & $€ 512(326-691)$ & $€ 493$ (337-644) \\
\hline
\end{tabular}

*All estimated costs per year were rounded to nearest whole UK£ unless otherwise indicated. Total direct medical costs are also calculated in US\$ and Euro $€$. AEDs: antiepileptic drugs; A\&E: accident and emergency; CT: computerised tomography; CYP: children and young people; GP: general practitioner; EEG:

electroencephalogram; MRI: magnetic resonance imaging. 
Table 4: Mean annual total direct medical costs per child according to sociodemographic factors of CYP with epilepsy

\begin{tabular}{|c|c|c|c|c|c|c|c|c|c|c|c|c|}
\hline \multirow{3}{*}{ Factors } & \multicolumn{12}{|c|}{ Years after epilepsy diagnosis (number of CYP) } \\
\hline & \multicolumn{3}{|c|}{$1^{\text {st }}$ year $(n=798)$} & \multicolumn{3}{|c|}{$2^{\text {nd }}$ year $(n=754)$} & \multicolumn{3}{|c|}{$3^{\text {rd }}$ year $(n=653)$} & \multicolumn{3}{|c|}{$4^{\text {th }}$ year $(n=530)$} \\
\hline & $\begin{array}{l}\text { Number } \\
\text { of CYP }\end{array}$ & $\begin{array}{l}\text { Mean cost* } \\
(95 \% \text { CI })^{\mathrm{a}}\end{array}$ & & $\begin{array}{l}\text { Number } \\
\text { of CYP }\end{array}$ & $\begin{array}{l}\text { Mean cost* } \\
(95 \% \mathrm{CI})^{\mathrm{a}}\end{array}$ & & $\begin{array}{l}\text { Number } \\
\text { of CYP }\end{array}$ & $\begin{array}{l}\text { Mean cost* } \\
(95 \% \mathrm{CI})^{\mathrm{a}}\end{array}$ & & $\begin{array}{l}\text { Number } \\
\text { of CYP }\end{array}$ & $\begin{array}{l}\text { Mean cost* } \\
(95 \% \mathrm{CI})^{\mathrm{a}}\end{array}$ & \\
\hline \multicolumn{13}{|l|}{ Sex } \\
\hline Male & 444 & $\begin{array}{r}£ 1027(940-1186) \\
\$ 1587(1453-1833) \\
€ 1226(1122-1416)\end{array}$ & $0.04^{\mathrm{b}}$ & 420 & $\begin{array}{r}£ 507(399-712) \\
\$ 784(617-1100) \\
€ 605(476-850)\end{array}$ & $0.36^{\mathrm{b}}$ & 363 & $\begin{array}{r}£ 521(375-794) \\
\$ 805(580-1227) \\
€ 622(448-948)\end{array}$ & $0.64^{\mathrm{b}}$ & 292 & $\begin{array}{r}£ 440(329-766) \\
\$ 680(509-1184) \\
€ 525(393-914)\end{array}$ & $0.18^{\mathrm{b}}$ \\
\hline Female & 354 & $\begin{array}{r}£ 808(718-935) \\
\$ 1249(1110-1445) \\
€ 964(857-1116)\end{array}$ & & 334 & $\begin{array}{l}£ 395(324-528) \\
\$ 611(501-816) \\
€ 471(387-630)\end{array}$ & & 290 & $\begin{array}{l}£ 415(324-567) \\
\$ 641(501-876) \\
€ 495(387-677)\end{array}$ & & 238 & $\begin{array}{r}£ 414(295-721) \\
\$ 640(456-1114) \\
€ 494(352-861)\end{array}$ & \\
\hline \multicolumn{13}{|c|}{$\begin{array}{l}\text { Age (years, time- } \\
\text { varying) }\end{array}$} \\
\hline$<2$ & 192 & $\begin{array}{r}£ 1203(992-1447) \\
\$ 1859(1533-2236) \\
€ 1436(1184-1727)\end{array}$ & $0.01^{\mathrm{c}}$ & 102 & $\begin{array}{l}£ 1007(619-1705) \\
\$ 1556(957-2635) \\
€ 1202(739-2035)\end{array}$ & $0.01^{\mathrm{c}}$ & 0 & - & & 0 & - & \\
\hline $2-6$ & 255 & $\begin{array}{r}£ 921(784-1112) \\
\$ 1423(1212-1719) \\
€ 1099(936-1327)\end{array}$ & & 248 & $\begin{array}{r}£ 478(371-659) \\
\$ 739(573-1019) \\
€ 570(443-787)\end{array}$ & & 259 & $\begin{array}{r}£ 743(508-1083) \\
\$ 1148(785-1674) \\
€ 887(606-1293)\end{array}$ & $0.02^{\mathrm{c}}$ & 175 & $\begin{array}{r}£ 697(428-1173) \\
\$ 1077(662-1813) \\
€ 832(511-1400)\end{array}$ & $0.05^{\mathrm{c}}$ \\
\hline $7-12$ & 303 & $\begin{array}{r}£ 810(706-954) \\
\$ 1252(1091-1475) \\
€ 967(843-1139)\end{array}$ & & 321 & $\begin{array}{l}£ 296(236-383) \\
\$ 457(365-592) \\
€ 353(282-457)\end{array}$ & & 306 & $\begin{array}{l}£ 306(244-407) \\
\$ 473(377-629) \\
€ 365(291-486)\end{array}$ & & 264 & $\begin{array}{l}£ 318(236-449) \\
\$ 492(365-694) \\
€ 380(282-536)\end{array}$ & \\
\hline$>12$ & 48 & $\begin{array}{r}£ 655(600-731) \\
£ 1012(927-1130) \\
€ 782(716-872)\end{array}$ & & 83 & $\begin{array}{r}£ 290(179-438) \\
448(277-677) \\
€ 346(214-523)\end{array}$ & & 88 & $\begin{array}{l}£ 270(170-373) \\
\$ 417(263-577) \\
€ 322(203-445)\end{array}$ & & 91 & $\begin{array}{l}£ 233(144-382) \\
\$ 360(223-590) \\
€ 278(172-456)\end{array}$ & \\
\hline
\end{tabular}

*All estimated costs per year were rounded to nearest whole UK£, US\$ and Euro $€$

a: bootstrapped bias corrected and accelerated confidence intervals $\quad$ b: t-test p-value on bootstrapped data

c: One way ANOVA p value on bootstrapped data

All estimated costs were rounded to nearest whole UK£. CI: confidence interval; CYP: children and young people. 


\section{Table 5: continued}

\begin{tabular}{|c|c|c|c|c|c|c|c|c|c|c|c|c|}
\hline \multirow[t]{2}{*}{ Factors } & \multicolumn{3}{|c|}{$1^{\text {st }}$ year $(n=798)$} & \multicolumn{3}{|c|}{$2^{\text {nd }}$ year $(n=754)$} & \multicolumn{3}{|c|}{$3^{\text {rd }}$ year $(n=653)$} & \multicolumn{3}{|c|}{$4^{\text {th }}$ year $(n=530)$} \\
\hline & $\begin{array}{l}\text { Number } \\
\text { of CYP }\end{array}$ & $\begin{array}{l}\text { Mean cost* } \\
(95 \% \mathrm{CI})^{\mathrm{a}}\end{array}$ & & $\begin{array}{l}\text { Number } \\
\text { of CYP }\end{array}$ & $\begin{array}{l}\text { Mean cost* } \\
(95 \% \mathrm{CI})^{\mathrm{a}}\end{array}$ & & $\begin{array}{l}\text { Number } \\
\text { of CYP }\end{array}$ & $\begin{array}{l}\text { Mean cost* } \\
(95 \% \mathrm{CI})^{\mathrm{a}}\end{array}$ & & $\begin{array}{l}\text { Number } \\
\text { of CYP }\end{array}$ & $\begin{array}{l}\text { Mean cost* } \\
(95 \% \mathrm{CI})^{\mathrm{a}}\end{array}$ & \\
\hline \multicolumn{13}{|l|}{ Townsend quintile } \\
\hline 1 (least deprived) & 147 & $\begin{array}{r}£ 813(673-1026) \\
\$ 1257(1040-1586) \\
€ 970(803-1225)\end{array}$ & $0.67^{\mathrm{c}}$ & 143 & $\begin{array}{l}£ 379(275-513) \\
\$ 586(425-793) \\
€ 452(328-612)\end{array}$ & $0.29^{c}$ & 119 & $\begin{array}{l}£ 329(215-503) \\
\$ 509(332-777) \\
€ 393(257-600)\end{array}$ & $0.71^{\mathrm{c}}$ & 91 & $\begin{array}{l}£ 376(234-571) \\
\$ 581(362-883) \\
€ 449(279-681)\end{array}$ & $0.93^{\mathrm{c}}$ \\
\hline 2 & 123 & $\begin{array}{r}£ 1095(837-1445) \\
\$ 1692(1294-2233) \\
€ 1307(999-1725)\end{array}$ & & 113 & $\begin{array}{r}£ 577(352-911) \\
\$ 892(544-1408) \\
€ 689(420-1087)\end{array}$ & & 102 & $\begin{array}{l}£ 397(233-645) \\
\$ 614(360-997) \\
€ 474(278-770)\end{array}$ & & 82 & $\begin{array}{l}£ 275(195-415) \\
\$ 425(301-641) \\
€ 328(233-495)\end{array}$ & \\
\hline 3 & 168 & $\begin{array}{r}920(759-1120) \\
\$ 1422(1173-1731) \\
€ 1098(906-1337)\end{array}$ & & 157 & $\begin{array}{l}£ 419(303-619) \\
\$ 648(468-957) \\
€ 500(362-739)\end{array}$ & & 133 & $\begin{array}{l}£ 411(256-585) \\
\$ 635(396-904) \\
€ 491(306-698)\end{array}$ & & 113 & $\begin{array}{r}£ 518(290-945) \\
\$ 801(448-1461) \\
€ 618(346-1128)\end{array}$ & \\
\hline 4 & 170 & $\begin{array}{r}998(811-1233) \\
\$ 1543(1253-1906) \\
€ 1191(968-1472)\end{array}$ & & 159 & $\begin{array}{r}£ 477(338-686) \\
\$ 737(522-1060) \\
€ 569(403-819)\end{array}$ & & 143 & $\begin{array}{l}£ 608(394-1030) \\
\$ 940(609-1592) \\
€ 726(470-1229)\end{array}$ & & 115 & $\begin{array}{r}£ 407(265-688) \\
\$ 629(410-1063) \\
€ 486(316-821)\end{array}$ & \\
\hline 5 (most deprived) & 135 & $\begin{array}{r}851(692-1072) \\
\$ 1315(1070-1657) \\
€ 1016(826-1279)\end{array}$ & & 129 & $\begin{array}{l}£ 405(255-562) \\
\$ 626(394-869) \\
€ 483(304-671)\end{array}$ & & 111 & $\begin{array}{r}£ 486(293-708) \\
\$ 751(453-1094) \\
€ 580(350-845)\end{array}$ & & 93 & $\begin{array}{l}£ 299(190-448) \\
\$ 462(294-692) \\
€ 357(227-535)\end{array}$ & \\
\hline Missing & 55 & $\begin{array}{r}£ 891(605-1415) \\
\$ 1377(935-2187) \\
€ 1063(722-1689)\end{array}$ & & 53 & $\begin{array}{r}£ 615(169-1869) \\
\$ 951(261-2889) \\
€ 734(202-2231)\end{array}$ & & 45 & $\begin{array}{r}£ 808(203-2400) \\
\$ 1249(314-3709) \\
€ 964(242-2864)\end{array}$ & & 36 & $\begin{array}{l}£ 1030(239-3070) \\
\$ 1592(369-4745) \\
€ 1229(285-3664)\end{array}$ & \\
\hline
\end{tabular}

*All estimated costs per year were rounded to nearest whole UK£, US\$ and Euro $€$

a: bootstrapped bias corrected and accelerated confidence intervals $\quad$ b: t-test p-value on bootstrapped data

c: One way ANOVA p value on bootstrapped data

All estimated costs were rounded to nearest whole UK£. CI: confidence interval; CYP: children and young people. 


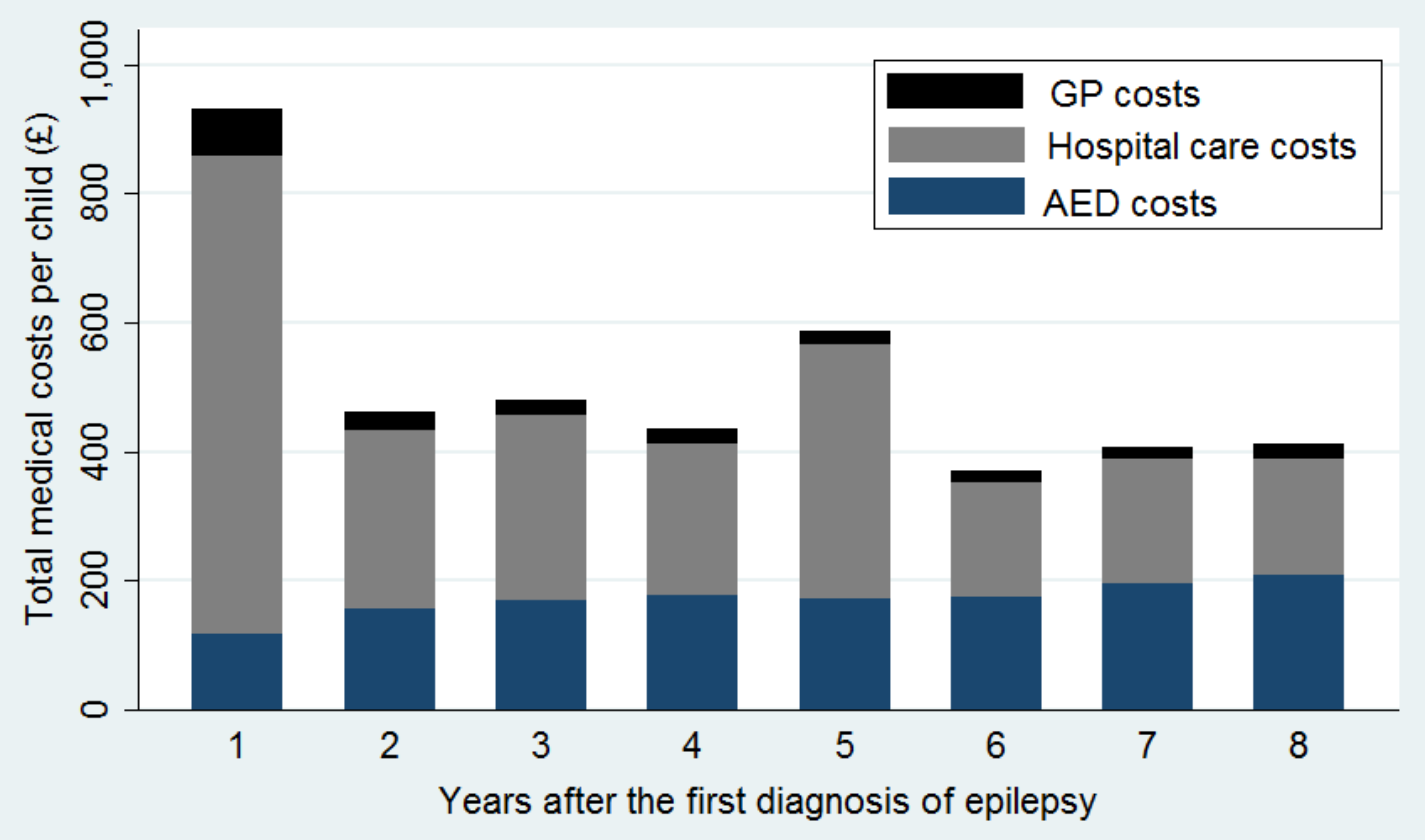

Figure 1: Total annual direct medical costs per child for CYP with epilepsy

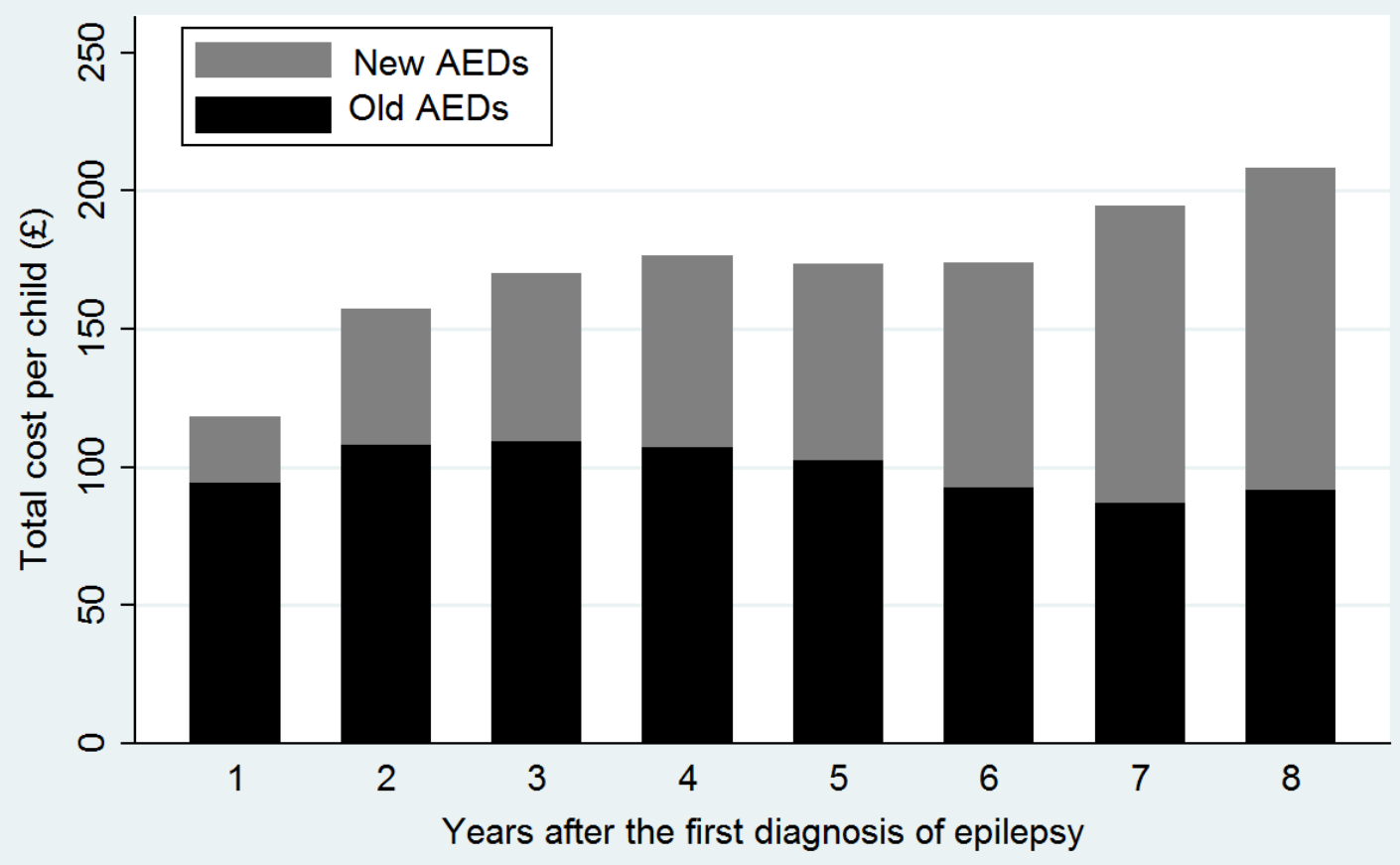

Figure 2: Total annual costs of old and new AEDs for CYP with epilepsy 


\section{References}

Ali, M. A. S. (2012). Investigating the Use of Medicines in Management of Children and Young People with Epilepsy. PhD thesis University of Nottingham

Beghi, E., Frigeni, B., Beghi, M., de Compadri, P., and Garattini, L. (2005). A Review of the Costs of Managing Childhood Epilepsy. Pharmacoeconomics, 23(1), 27-45.

BNF (2011). The British National formulary for children (Eds.). London-UK: BMJ Publishing Group and Pharmaceutical Press Ltd.

Briggs, A., and Gray, A. (1998). The distribution of health care costs and their statistical analysis for economic evaluation. Journal of health services research \& policy, 3(4), 233-45.

Cockerell, O. C., Hart, Y. M., Sander, J. W. A. S., and Shorvon, S. D. (1994). The cost of epilepsy in the United Kingdom: An estimation based on the results of two population-based studies. Epilepsy Research, 18(3), 249-60.

Curtis, L. (2011) Personal Social Services Research Unit- Unit Costs of Health and Social Care [Online][Accessed 2 March 2012]. The University of KentCanterbury. Available: http://www.pssru.ac.uk/pdf/uc/uc2011/uc2011.pdf.

Department of Health. 2010-11 reference costs publication. [Online][Accessed 2 March 2012]. Available:

http://www.dh.gov.uk/en/Publicationsandstatistics/Publications/PublicationsP olicyAndGuidance/DH_131140.

Forsgren, L., Beghi, E., Oun, A., and Sillanpää, M. (2005). The epidemiology of epilepsy in Europe - a systematic review. European Journal of Neurology, 12245-53.

Guerrini, R. (2006). Epilepsy in children. Lancet, 367(9509), 499-524.

Guerrini, R., Battini, R., Ferrari, A. R., Veggiotti, P., Besana, D., Gobbi, G., Pezzani, M. (2001). The Costs of Childhood Epilepsy in Italy: Comparative Findings from Three Health Care Settings. Epilepsia, 42(5), 641-46.

ILAE. (1989). Commission on Classification and Terminology of the International League Against Epilepsy. Proposal for revised classification of epilepsies and epileptic syndromes. Epilepsia, 30(4), 389-99.

International Statistical Classification of Diseases and Related Health Problems-10th 2007. [Online][Accessed 12 July 2009]. Available: http://apps.who.int/classifications/apps/icd/icd10online/.

Jacoby, A., Buck, D., Baker, G., McNamee, P., Graham-Jones, S., and Chadwick, D. (1998). Uptake and Costs of Care for Epilepsy: Findings from a U.K. Regional Study. Epilepsia, 39(7), 776-86.

Jette, N., Quan, H., Faris, P., Dean, S., Li, B., Fong, A., and Wiebe, S. (2008). Health resource use in epilepsy: Significant disparities by age, gender, and aboriginal status. Epilepsia, 49(4), 586-93.

Jordan, H., Roderick, P., and Martin, D. (2004). The Index of Multiple Deprivation 2000 and accessibility effects on health. Journal of Epidemiology and Community Health, 58(3), 250-57.

Kotsopoulos, I. A., van Merode, T., Kessels, F. G. H., de Krom, M. C. T. F. M., and Knottnerus, J. A. (2002). Systematic Review and Meta-analysis of Incidence Studies of Epilepsy and Unprovoked Seizures. Epilepsia, 43(11), 1402-09.

Meeraus, W. H., Petersen, I., Chin, R. F., Knott, F., and Gilbert, R. (2013). Childhood epilepsy recorded in primary care in the UK. Archives of Disease in Childhood, 98(3), 195-202. 
Morgan, C. L., and Kerr, M. P. (2004). Estimated Cost of Inpatient Admissions and Outpatient Appointments for a Population with Epilepsy: A Record Linkage Study. Epilepsia, 45(7), 849-54.

Morgan, C. L. I., Ahmed, Z., and Kerr, M. P. (2000). Social deprivation and prevalence of epilepsy and associated health usage. Journal of Neurology, Neurosurgery \& Psychiatry, 69(1), 13-17.

National Health Service. Elecronic Drug Tariff. [Online][Accessed 8 January 2012]. Available: http://www.ppa.org.uk/edt/January_2012/mindex.htm.

Pugliatti, M., Beghi, E., Forsgren, L., Ekman, M., and Sobocki, P. (2007). Estimating the Cost of Epilepsy in Europe: A Review with Economic Modeling. Epilepsia, 48(12), 2224-33.

Stokes, T., Shaw, E., Juarez-Garcia, A., Camosso-Stefinovic, J., and Baker, R. (2004) Clinical Guidelines and Evidence Review for the Epilepsies: diagnosis and management in adults and children in primary and secondary care.

[Online][Accessed 20 March 2009]. Available: http://www.nice.org.uk/Guidance/CG20.

Stuart-Buttle, C. D., Read, J. D., Sanderson, H. F., and Sutton, Y. M. (1996). A language of health in action: Read Codes, classifications and groupings. Proceedings AMIA Annual Fall Symposium, 75-79.

The Health Improvement Network database [Online][Accessed 5 July 2012]. Available: http://csdmruk.cegedim.com/our-data/statistics.html.

Wallace, H., Shorvon, S., and Tallis, R. (1998). Age-specific incidence and prevalence rates of treated epilepsy in an unselected population of 2052922 and age-specific fertility rates of women with epilepsy. The Lancet, 352(9145), 1970-73. 